\title{
HUBUNGAN TINGKAT STRES DENGAN SIKLUS MENSTRUASI PADA SISWI KELAS XII SMA N 5 KOTA BENGKULU
}

\author{
Febby Novriani, Ismiati, Lusi Andriani \\ Politeknik Kesehatan Kementerian Kesehatan Bengkulu, Jurusan kebidanan \\ Jalan Indragiri No. 3 Padang Harapan Bengkulu \\ ismiatidzaky@gmail.com
}

\begin{abstract}
Adolescence period is an important period in the life span of adolescents when they are experiencing a transitional period of individual in finding into adulthood. The early years of menstruation are the period that susceptible to disturbance, $75 \%$ of women in adolescent have sustain disorder with menstruation that is irregular menstruation. The purpose of this study was to determine the correlation between stress and we menstrual cycle in female students of XII classes at SMA N 5 Bengkulu City 2014. The study design that used was Descriptive Analytic design by using cross sectional, population in this study were all female students of class XII consist of 106 people, technique sampling used total sampling. Data Analysis were univariate and bivariate. The results showed that almost all respondents $(84.2 \%)$ have irregular menstrual patterns. The results of the chi square expressed the relationship and stress levels and the menstrual cycle $(p=0.000)$ It is recommended to the school as a place of education for girls, school is expected to assist the student information about how to prevent the occurrence of stress, arrenge schedule with considence in getting relax and rest time for girls student do not that student does not feel burdened with activities and school schedules both in academic and non-academic, to reduce the risk of stress on the students.
\end{abstract}

Keywords: Menstrual Cycle, Stress Levels

\begin{abstract}
Abstrak : Masa remaja merupakan masa yang penting dalam rentang kehidupan dimana remaja mengalami suatu periode peralihan dimana individu mencari identitas (jati diri) menuju masa dewasa. Tahun-tahun awal menstruasi merupakan periode yang rentan terhadap terjadinya gangguan, $75 \%$ wanita pada remaja mengalami gangguan yang terkait dengan menstruasi yaitu menstruasi tidak teratur. Tujuan penelitian ini adalah mengetahui hubungan tingkat stres dengan siklus menstruasi pada siswi kelas XII di SMA N 5 Kota Bengkulu tahun 2014. Desain penelitian yang digunakan adalah desain deskriptif analitik dengan menggunakan pendekatan Cross Sectional, populasi dalam penelitian ini adalah seluruh siswi kelas XII 106 orang, teknik pengambilan sampel secara total sampling. Analisis data secara univariat dan bivariat. Hasil penelitian menunjukkan dari 38 responden yang tingkat stresnya kategori sedang hampir seluruh responden $(84,2 \%)$ siklus menstruasinya tidak normal. Hasil uji chi square menyatakan ada hubungan tingkat stres dengan siklus menstruasi $(p=0,000)$. Disarankan kepada sekolah sebagai wadah pendidikan bagi siswi, lebih diharapkan dapat turut membantu dalam informasi terhadap siswi tentang cara pencegahan terhadap terjadinya stres, mengatur jadwal dengan mempertimbangkan waktu rileks dan istirahat bagi siswi agar siswi tidak merasa terbebani dengan kegiatan dan jadwal sekolah baik akademik maupun non akademik untuk mengurangi resiko stres pada siswi.
\end{abstract}

Kata Kunci : Siklus Menstruasi, Tingkat Stres

Masa remaja merupakan masa yang penting dalam rentang kehidupan dimana remaja mengalami suatu periode peralihan, suatu masa perubahan, usia bermasalah dan saat dimana individu mencari identitas (jati diri) menuju masa dewasa (Murwani, 2008). Hal yang paling penting dari siklus kehidupan pada remaja adalah puberitas. Pada remaja putri puberitas ditandai dengan menarche yaitu mentruasi pertama, biasanya rata-rata pada usia 8-14 tahun. Menstruasi yang berulang setiap bulan akhirnya membentuk siklus menstruasi. Siklus menstruasi dihitung dari hari pertama menstruasi sampai tepat satu hari sebelum menstruasi bulan berikutnya. Siklus menstruasi berkisar antara 25-35 hari. 
Gangguan pada siklus menstruasi dipengaruhi oleh gangguan pada fungsi hormon, kelainan sistemik, stres, kelenjar gondok, dan hormon prolaktin yang berlebihan. Gangguan pada siklus menstruasi pendek yang disebut juga dengan polimenorea, siklus menstruasi panjang atau oligomenorea, dan amenorea jika tidak terjadi menstruasi dalam tiga bulan berturut-turut (Winkjosastro, 2007).

Stres dapat mempengaruhi sistem hormonal pada sistem reproduksi yaitu dalam pengaruhnya terhadap pola menstruasi, stres melibatkan sistem neuroendokrin sebagai sistem yang besar perananya dalam reproduksi wanita. Stress pada wanita akan mengaktifan HPA aksis, mengakibatkan hipotalamus menyekresikan Cortocoptopin Relaxing Hormone (CRH). CRH mempunyai pengaruh negatif terhadap pengaturan sekresi GnRH, ketidaksimbangan CRH memiliki pengaruh terhadap penekanan fungsi reproduksi. Sekresi CRH ini akan merangsang pelepasan ACTH oleh hipofisis anterior yang selanjutnya ACTH akan merangsang kelenjar adrenal untuk menyekresikan kortisol. Pengaruh hormon kortisol ini menyebabkan terjadinya ketidakseimbangan hormon yang mengakibatkan siklus menstruasi menjadi tidak teratur (Jones, 2005).

Stres jangan dianggap remeh sebab akan mengganggu sistem metabolisme di dalam tubuh. Bisa saja karena stres, terjadi mudah lelah, berat badan turun drastis, bahkan sakitsakitan, sehingga metabolismenya terganggu. Bila metabolisme terganggu, siklus haid pun ikut terganggu (Klinik Sehat, 2008). Penelitian ini secara umum bertujuan untuk mengetahui hubungan tingkat stres dengan pola menstruasi pada siswi kelas XII di SMA N 5 Kota Bengkulu tahun 2014.

\section{BAHAN DAN CARA KERJA}

Desain penelitian yang digunakan adalah desain penelitian deskriptif analitik dengan menggunakan pendekatan Cross Sectional. Populasi dalam penelitian ini adalah seluruh siswi kelas XII terdiri dari 6 (enam) kelas di SMA N 5 Bengkulu yang berjumlah 106 orang. Teknik pengambilan sampel menggunakan teknik total sampling, sehingga jumlah sampel sebanyak 106. Pengumpulan data pada penelitian ini menggunakan kuesioner untuk mengetahui hubungan antara Tingkat Stres Dengan Tingkat Stres pada siswi kelas XII di SMA N 5 Kota Bengkulu tahun 2014.

\section{HASIL}

\section{Analisa Univariat}

Analisa Univariat dilakukan untuk melihat distribusi frekuensi pada masing-masing variabel penelitian yaitu tingkat stres sebagai variabel independen dan pola menstruasi sebagai variabel dependen. Adapun hasil penelitian dapat dilihat pada tabel berikut :

Tabel 1. Distribusi frekuensi responden menurut tingkat stres siswi kelas XII di SMA 5 Kota Bengkulu Tahun 2014

\begin{tabular}{lcc}
\hline \multicolumn{1}{c}{ Variabel } & $\begin{array}{c}\text { Frekuensi } \\
(\mathbf{n = 1 0 6})\end{array}$ & Persen \\
\hline Tingkat Stres & & \\
- Sedang & 38 & 35,8 \\
- Ringan & 68 & 64,2 \\
Siklus Mestruasi & 33 & 31,1 \\
- Tidak Normal & 73 & 68,9 \\
- Normal & & \\
\hline
\end{tabular}

Dari tabel 1 dapat dilihat bahwa hampir sebagian responden $(35,8 \%)$ dengan tingkat stress kategori sedang dan hampir sebagian $(31,1 \%)$ responden memiliki siklus mentruasi tidak normal

\section{Analisis Bivariat}

Analisis bivariat dilakukan untuk mengetahui hubungan variabel independen (tingkat stres) dengan variabel dependen (siklus menstruasi), dengan menggunakan uji statistik chi square pada $\alpha(0,05)$. Hasil penelitian dapat dilihat pada tabel berikut:

Tabel 2. Hubungan Tingkat Stres dengan Siklus Menstruasi pada Siswi Kelas XII di SMA N 5 Kota Bengkulu Tahun 2014

\begin{tabular}{|c|c|c|c|c|c|c|c|}
\hline \multirow{3}{*}{$\begin{array}{c}\text { Tingkat } \\
\text { Stres }\end{array}$} & \multicolumn{4}{|c|}{ Siklus Menstruasi } & \multirow{2}{*}{\multicolumn{2}{|c|}{ Total }} & \multirow{3}{*}{$\begin{array}{c}P \\
\text { value }\end{array}$} \\
\hline & \multicolumn{2}{|c|}{$\begin{array}{c}\text { Tidak } \\
\text { Normal }\end{array}$} & \multicolumn{2}{|c|}{ Normal } & & & \\
\hline & $\mathbf{f}$ & $\%$ & $\mathbf{f}$ & $\%$ & f & $\%$ & \\
\hline Sedang & 32 & 84,2 & 6 & 15,8 & 38 & 100 & \\
\hline Ringan & 1 & 1,5 & 67 & 98,5 & 68 & 100 & 0,000 \\
\hline Jumlah & 33 & 31,1 & 73 & 68,9 & 106 & 100 & \\
\hline
\end{tabular}

Tabel 2 dari 38 responden yang tingkat stresnya kategori sedang hampir seluruh responden $(84,2 \%)$ siklus menstruasinya tidak 
normal. Dari hasil uji chi square menunjukkan bahwa nilai $p=0,000$, berarti ada hubungan tingkat stres dengan siklus menstruasi pada siswi kelas XII di SMA N 5 Kota Bengkulu tahun 2014

\section{PEMBAHASAN}

\section{Tingkat Stress}

Hasil analisis univariat menunjukkan bahwa hampir sebagian dari responden $(35,8 \%)$ dengan tingkat stres sedang. Hal ini didapat berdasarkan pengumpulan data menggunakan kuesioner yang disebar kepada siswi kelas XII, dengan gejala tersering yang dialami oleh siswi pada tingkat stres sedang berupa sering marah karena hal-hal sepele, mudah merasa kesal. mudah tersinggung. sangat mudah marah.dan merasa gelisah. Stres adalah suatu keadaan yang dihasilkan oleh perubahan lingkungan yang diterima sebagai satu hal yang menantang, mengancam atau merusak terhadap keseimbangan atau equilibrium dinamis seseorang. Ada ketidakseimbangan nyata atau semu pada kemampuan seseorang dalam memenuhi permintaan situasi yang baru. Perubahan atau stimulus yang membangkitkan keadaan tersebut adalah stressor (Suddarth, 2001). Tingkat stres adalah hasil penilaian terhadap berat ringannya stres yang dialami seseorang. Tingkatan stres dapat diukur menggunakan alat ukur yang disebut Depression Anxiety Stress Scale (DASS).

\section{Siklus Menstruasi}

Hasil penelitian menunjukkan bahwa hampir sebagian $(31,1 \%)$ responden memiliki siklus mentruasi tidak teratur. Hal ini berdasarkan jawaban siswi yang didapat dari kuesioner. Haid atau menstruasi adalah pelepasan dinding rahim (endometrium) yang disertai dengan perdarahan dan terjadi berulang setiap bulan kecuali pada saat kehamilan. Menstruasi merupakan masa reproduktif pada kehidupan seorang wanita, yang dimulai dari menarche sampai terjadinya menopause (Fitria, 2007).

Siklus menstruasi merupakan suatu siklus menstruasi normal, dengan menarche sebagai titik awal. Pada umumnya menstruasi akan berlangsung setiap 28-35 hari selama lebih kurang
7 hari. Lama perdarahannya sekitar 3-5 hari, ada 1-2 hari diikuti darah yang sedikit-sedikit dan tidak terasa nyeri. Jumlah darah yang hilang sekitar 30-40cc. puncaknya hari ke-2 atau ke-3 dengan jumlah pemakaian pembalut sekitar 2-3 buah (Manuaba, 2010).

\section{Hubungan Tingkat Stres dengan Siklus Men- struasi}

Berdasarkan hasil penelitian dari 38 responden yang tingkat stresnya kategori sedang hampir seluruh dari responden $(84,2 \%)$ dari responden pola siklus menstruasinya tidak normal. Dari hasil uji chi square menunjukkan bahwa nilai $p=0,000$, berarti terdapat hubungan tingkat stres dengan siklus menstruasi pada siswi kelas XII di SMA N 5 Kota Bengkulu tahun 2014. Hal ini sesuai dengan pendapat Jones, 2005 yang memaparkan bahwa pada keadaan stres terjadi pengaktifan Hypothalamic Pitutary adrenal (HPA) aksis, mengakibatkan hipotalamus menyekresikan Cortocoptopin Relaxing Hormone (CRH). $\mathrm{CRH}$ mempunyai pengaruh negatif terhadap pengaturan sekresi GnRH, ketidaksimbangan CRH memiliki pengaruh terhadap penekanan fungsi reproduksi manusia sewaktu stres. Sekresi CRH ini akan merangsang pelepasan ACTH oleh hipofisis anterior yang selanjutnya ACTH akan merangsang kelenjar adrenal untuk menyekresikan kortisol. Pengaruh hormon kortisol ini menyebabkan terjadinya ketidakseimbangan hormon yang mengakibatkan siklus menstruasi menjadi tidak teratur.

Pada wanita yang mengalami stres akan terjadi keadaan yang menggangu homeosstatis. Status reproduktif merupakan cerminan keadaan psikologis seseorang, apabila terjadi peningkatan paparan stres, fungsi reproduktif akan otomatis mengalami penurunan untuk mempertahankan homeostatis tubuh. System stres diatur oleh Hypothalamic Pitutary adrenal (HPA) axis dan system autonomic. Mediator utama system stres antara lain Cortocoptopin Relaxing Hormone (CRH), glicorcorticoids, dan beta endhorphine. CRH memiliki berbagai jaringan seperti ovarium, endometrium, hypothalamus dan jaringan inflammatory. Peningkatan prodiksi CRH dan kortisol meyebabkan pembatasan sekresi GnRH dan secara konsek- 
uen turut menurunkan ovulasi. Penuruanan masa ovulasi ini akan mempengaruihi lama masa proliferasi dan sekresi sehingga berpenaruh pada siklus mentruasi (Rakhmawati, 2012).

\section{KESIMPULAN}

Berdasarkan hasil penelitian maka dapat disimpulkan bahwa hampir sebagian dari siswi kelas XII di SMA N 5 Kota Bengkulu tahun 2014 dengan tingkat stres kategori sedang dan hampir sebagian siswi kelas XII di SMA N 5 Kota Bengkulu tahun 2014 memiliki pola mentruasi tidak teratur. Jadi, ada hubungan tingkat stres dengan pola menstruasi pada siswi kelas XII di SMA N 5 Kota Bengkulu tahun 2014. Berdasarkan hasil penelitian dan pembahasan peneliti ingin memberikan saran kepada beberapa pihak yang terkait antara lain kepada akademisi, sekolah dan peneliti lain.

Sebagai salah satu Institusi di bidang kesehatan para akademisi diharapkan dapat ikut

\section{DAFTAR RUJUKAN}

Arikunto, S. 2009. Prosedur penelitian Suatu Pendekatan Praktik. Jakarta: Rineka Cipta.

Alimul, A. A. 2008. Pengantar Kebutuhan Dasar Manusia, Jakarta: Salemba Medika

Bobak, M. I. dkk. 2005. Buku Ajar Keperawatan Maternitas Edisi 4. Jakarta: EGC

Cakir, M, dkk. 2007. Menstrual Pattern And Common Menstrual Disorder Among University Students In Turkey. Pediatrics International; 49 (6). 938-42

Dadang. 2006. Manajemen Stres Cemas dan Depresi. Jakarta: Balai Penerbit FKUI

Djiwandono, 2002. Psikologi Pendidikan. Jakarta: PT Grasindo

Fitria, A. 2007. Panduan Lengkap Kesehatan Wanita. Yokyakarta: Gala Ilmu Semesta

Gunawan, dkk. 2007. Stres dan Sistem Imun Tubuh. Jakarta: Cermin Dunia Kedokteran

Jones, D. L. 2005. Setiap Wanita: Buku Panduan Lengkap tentang Kesehatan, Kebidanan dan Kandungan. Jakarta: Delapratasa Publishing

Kartono, K. 2009. Psikologi Wanita 1: Mengenal Gadis Remaja dan Wanita Dewasa. Bandung: Bandar Maju.

Karout, N, dkk. 2012. Prevalence and Pattern Of Menstrual Disorders Among Lebanese Nursing Students. Eastern Mediterranean Health Journal La Revue De Santé De La Méditerranée Orientale EMHJ. Vol. 18 No. 4.2012

Klinik Sehat 2008. Siklus Haid Tidak Teratur. diakses pada 5 Januari 2014 serta memberikan informasi kepada siswi tentang dampak ganggaun psikologi khususnya keadaan stres dengan keadaan kesehatan reproduksi seperti pola menstruasi. Sebagai wadah pendidikan bagi siswi, sekolah lebih diharapkan dapat turut membantu dalam informasi terhadap siswi tentang cara pencegahan terhadap terjadinya stres, mengatur jadwal dengan mempertimbangkan waktu rileks dan instirahat bagi siswi agar siswi tidak merasa terbebani dengan kegiatan dan jadwal sekolah baik akademik maupun non akademik untuk mengurangi resiko stres pada siswi. Diharapkan pada peneliti lain untuk melakukan penelitian lebih lanjut tentang faktor-faktor lain yang dapat menebabkan pola menstruasi tidak teratur seperti gangguan sistemik, terganggunya fungsi kelenjar gondok/tiroid, dan gangguan hormone lainnya dengan metode lain seperti kohort dan eksperimen.

Kusmiran, E. 2011. Kesehatan Reproduksi Remaja Dan Wanita. Jakarta: Salemba Medika.

Lovibond \& Lovibond, P.f. 2003. Manual For The Depression Anxiety Stress Scales. Sydney: Psychologi Foundation

Manuaba, I. B. G. 2010. Memahami Kesehatan Reproduksi Wanita. Jakarta: EGC.

Murwani, A. 2008. Pengantar Konsep Dasar Keperawatan. Yogyakarta: Fitramaya.

Notoatmodjo, S. 2005. Metodologi Penelitian Kesehatan. Jakarta: Rineka Cipta.

Nursalam. 2003. Konsep Dan Penerapan Metodologi Penelitian Ilmu Keperawatan. Jakarta: salemba medica

Potter, Perry. 2010. Fundamental keperawatan. Jakarta: Salemba Medika

Prawirohardjo, S. 2010. Ilmu Kandungan. Jakarta: Yayasan Bina Pustaka.

Rakhmawati, A. 2012, Hubungan Obesitas dengan Kejadian Gangguan Siklus Menstruasi pada Wanita Dewasa Muda. Journal of Nutrision Colegge Voulume 2 Nomor 1 Tahun 2013 Hal 214-222.

Saryono, Waluyo. 2009. Sindrom Premenstruasi. Yogjakarta: PT. NuhaMedika.

Soetjiningsih. 2007. Buku Ajar Tumbuh Kembang Remaja dan Permasalahannya. Jakarta: Sagung Seto

Sogi, D. 2011, Faktor-Faktor Yang Berhubungan Dengan Siklus Menstruasi Pada Mahasiswa Akbid Sari Mulya Banjarmasin Tahun 2011. Media Sains Volume 5 Nomor 1, April 2013 ISSN 2085-3548. 
Sianipar, O, dkk. 2009. Prevalensi Gangguan Menstruasi dan Faktor-Faktor yang Berhubungan pada Siswi SMU di Kecamatan Pulo Gadung Jakarta Timur. Majalah Kedokteran Indonesia, Volume: 59, Nomor: 7, Juli 2009. diakses pada 21 Januari 2014.
Suddarth. 2001. Keperawatan Medikal Bedah Edisi 8 Volume2. Jakarta: EGC

Winkjosastro, Hanifa, 2007. Ilmu Kebidanan, revisi ke tujuh YBP-SP. Jakarta: 